\title{
Compensation for lateral drift due to crosswind in migrating European Bee-eaters
}

\author{
Nir Sapir • Nir Horvitz • Martin Wikelski • \\ Roni Avissar $\cdot$ Ran Nathan
}

\begin{abstract}
Billions of seasonally migrating birds and insects use two principal modes of flight, i.e., flapping and soaring gliding. Flight mode is known to have strong effects on energy expenditure and speed of migration, yet its influence on the migratory track has rarely been investigated. Using radio telemetry, we studied the effects of crosswind on European Bee-eaters (Merops apiaster) during their spring migration with respect to different flight modes. Flapping, soaring gliding, and mixed flight in which the birds flapped during gliding were distinguished by radio signals while the birds were flying en route over southern Israel. The regional atmospheric modeling system was applied in high spatial $(1 \mathrm{~km} \times 1 \mathrm{~km})$ and temporal
\end{abstract}

N. Sapir · N. Horvitz · R. Nathan

Movement Ecology Laboratory, Department of Ecology,

Evolution and Behavior, Alexander Silberman Institute of Life

Sciences, The Hebrew University of Jerusalem, Edmond J. Safra campus, 91904 Giv'at Ram, Jerusalem, Israel

Present Address:

N. Sapir $(\square)$

National Natural History Collections, The Hebrew University of Jerusalem, Edmond J. Safra Campus,

91904 Giv'at Ram, Jerusalem, Israel

e mail: nir.sapir@mail.huji.ac.il

\section{Wikelski}

Max Planck Institute for Ornithology, 'Vogelwarte Radolfzell' Schlossallee 2, 78315 Radolfzell, Germany

\section{Wikelski}

Department of Biology, Konstanz University, 78315 Constance, Germany

\section{R. Avissar}

Rosenstiel School of Marine and Atmospheric Science, University of Miami, 4600 Rickenbacker Causeway, Miami, FL 33149 1098, USA
(5 min) resolution to estimate winds encountered aloft. We analyzed data from 11 birds that flew over a total distance of $810 \mathrm{~km}$ and found that lateral drift due to side wind did not differ among birds engaged in different flight modes. Overall, there was almost no effect of crosswind speed on bird lateral speed, as the regression slope was 0.31 (indicting mild lateral drift) and the regression's $R^{2}$ was 0.01. Therefore, we conclude that migrating bee-eaters compensated for crosswind during their spring migration and that this response was not dependent on bird flight mode.

Keywords Atmospheric modeling · Biotelemetry · Bird migration · Flight mode $\cdot$ Merops apiaster . Wind drift

\section{Zusammenfassung}

Ziehende Bienenfresser kompensieren die durch Seitenwinde verursachte seitliche Abdrift

Milliarden saisonal migrierender Vögel und Insekten benutzen zwei unterschiedliche Flugtechniken, den Ruderflug und den Segel- und Gleitflug. Es ist bekannt, dass die Flugtechnik die Energiekosten und die Geschwindigkeit der Zuges stark beeinflusst. Der Einfluss der Flugtechnik auf die Migrationsroute wurde bisher jedoch kaum untersucht. Mittels Radiotelemetrie haben wir den Einfluss von Seitenwinden auf den Frühjahrszug von Bienenfressern (Merops apiaster) untersucht. Während die Vögel über Südisrael flogen, konnten Ruderflug, Segel- und Gleitflug und Flügelschlag während des Gleitfluges aufgrund der Funksignale unterschieden werden. Das Regional Atmospheric Modeling System wurde mit einer hohen räumlichen $(250 \mathrm{~m} \times 250 \mathrm{~m})$ und zeitlichen (5 Minuten) Auflösung angewandt um die auftretenden Winde zu 
berechnen. Die Daten von elf Vögeln, die eine Gesamtstrecke von $810 \mathrm{~km}$ geflogen sind, wurden von uns analysiert. Die seitliche Abdrift durch Seitenwinde unterschied sich nicht zwischen den unterschiedlichen Flugtechniken. Es gab insgesamt fast keinen Effekt der Geschwindigkeit der Seitenwinde auf die Geschwindigkeit der seitlichen Abdrift der Vögel. Die Steigung der Regressionsgerade war 0,31 (was nur geringe seitliche Abdrift anzeigt) und $R^{2}$ der Regression war 0,01. Daraus schließen wir, dass die migrierenden Bienenfresser während ihres Frühjahrszugs Seitenwinde kompensiert haben und dass die Flugtechnik keinen Einfluss auf diese Kompensation hatte.

\section{Introduction}

Billions of birds and insects travel twice a year between different locations on the globe (Williams 1957; Newton 2007). To accomplish any migratory journey, migrants must be able to control their flight speed and energy stores (Alerstam and Lindström 1990; Hedenström and Alerstam 1995) while progressing towards their destination. Since their net geographical translocation during flight does not only depend on their own movement but also on that of the air through which they are flying, winds may profoundly affect their flight speed and direction (Alerstam 1979; Liechti and Bruderer 1998; Liechti 2006). Specifically, flight in crosswinds may cause migrants to drift sideways from their intended migration path (Richardson 1978, 1990; Green 2001; Thorup et al. 2003; Liechti 2006; but see Cochran 1987; Chapman et al. 2008; Karlsson et al.
2010), possibly incurring energy and time costs, as well as navigational challenges in reaching their end-of-migration destinations (Alerstam and Hedenström 1998; Green 2001). To minimize the degree of lateral drift, flight may take place only at certain times and altitudes at which the wind is either weak or blowing from a direction that assists the migrants in reaching their goal areas (Drake and Farrow 1988; Bruderer and Liechti 1995; Chapman et al. 2008, 2010; but see Gudmundsson et al. 2002; Pennycuick et al. 2011). However, migrating birds of various taxa are commonly found flying under strong crosswinds (Alerstam 1975; Richardson 1978, 1990; Cochran 1987; Green 2001; Thorup et al. 2003; Liechti 2006; Klaassen et al. 2011).

When flying in crosswind, animals may either drift (fully or partially) sideways or maintain their movement towards their intended destination. In the latter case, animals must compensate for wind drift by heading into the wind during movement, and this also applies for cases of partial drift in which animals also head into the wind, but to a lesser extent (Alerstam 1979; Srygley et al. 1996; Riley et al. 1999; Chapman et al. 2008, 2010; Karlsson et al. 2010; Alerstam et al. 2011; Klaassen et al. 2011; Fig. 1). Yet, wind drift compensation is not desirable when the crosswind direction is highly variable between different flight segments because under such a scenario, sideways drifts may cancel each other and may not cause substantial overall lateral drift (Cochran 1987; Cochran and Wikelski 2005). In addition, when animals are limited in their ability to establish their intended goal relative to their position, full compensation for wind drift may not be possible. For example, limited visibility may pose navigational challenges for animals that use landmarks to establish their
Fig. 1 Illustration of bird strategy in relation to crosswind during flight. a Lateral drift due to crosswind, b no lateral drift due to compensation of drift by a change in flight direction towards the incoming wind. Crosswind velocity in this illustration is half that of the bird's own velocity (Liechti and Bruderer 1998) a

Bird destination

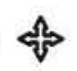

Bird heading vector

Bird track vector



b Bird destination
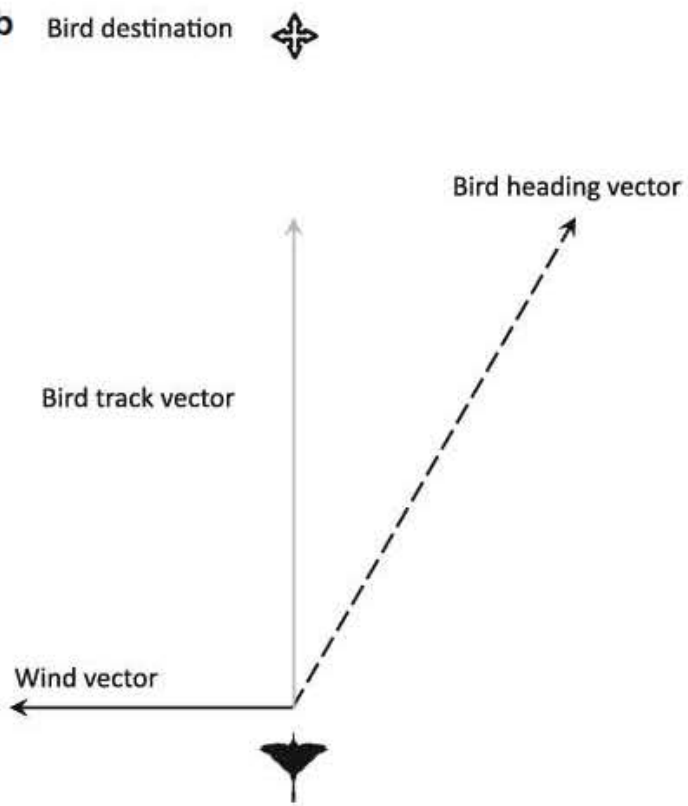
location (Richardson 1978, 1990). Indeed, flying animals have been found to substantially drift sideways under a dearth of landmarks (Alerstam 1975; Srygley 2001; Srygley and Dudley 2008).

Bird and butterfly migrants are known to use two principal modes of flight, i.e., flapping and soaring gliding (Gibo and Pallett 1979; Alerstam 1990; Pennycuick 2008). During flapping, thrust is produced by wing movements, while during soaring gliding, horizontal progress is achieved mostly by descending (i.e., gliding) after the animal has ascended by exploiting updrafts (i.e., soaring), such that soaring gliding can be described as a repeated cycle which involves circling in a thermal to climb and then losing height in a straight glide (Pennycuick 1972; Pennycuick et al. 1979; Shamoun-Baranes and van Loon 2006; Bohrer et al. 2012; Duerr et al. 2012). Empirical findings suggest that soaring gliding is energetically less demanding than flapping (Baudinette and Schmidt-Nielsen 1974; Bevan et al. 1995; Sapir et al. 2010), presumably at the expense of being overall slower (Pennycuick 1972; Hedenström 1993; but see Sapir et al. 2010). To date, the influence of animal flight mode on the migratory track has rarely been investigated (but see Duerr et al. 2012 for a comparison between soaring gliding and slope soaring flight modes). We suggest that animals engaging in different flight modes may respond differently to crosswind because different flight modes involve specific flight mechanisms, altitudinal range (Pennycuick 1972; Shamoun-Baranes et al. 2006; Duerr et al. 2012), and directionality (e.g., soaring flight involves spiral circling while flight direction is usually constant during flapping). Moreover, each flight mode usually takes place under certain atmospheric conditions (Shamoun-Baranes et al. 2006; Sapir et al. 2011b; Bohrer et al. 2012). Specifically for migrating bird species employing flapping flight, wind speed was found to negatively affect flight altitude (Shamoun-Baranes et al. 2006; Thomas et al. 2011), possibly because wind speed is lower near the surface due to friction (Stull 1988), and flapping birds may actively select to move close to the surface in order to reduce the negative influence of both headwinds and crosswinds. Indeed, under strong headwinds and crosswinds, migrating European Bee-eaters fly very close (approx. $1 \mathrm{~m}$ ) to the ground using flapping flight (N. Sapir, personal observation). However, flight close to the ground may limit visibility of landmarks during flight, possibly restricting the birds' ability to compensate for lateral drift.

To explore the relationship between lateral drift due to crosswind and bird flight mode, we tracked European Beeeaters (Merops apiaster) in southern Israel during their spring migration. European Bee-eaters are long-distance migrants that breed in southern Europe and southwestern Asia and spend the winter in sub-Saharan Africa. Using portable radio telemetry systems, we were able to distinguish between flight modes based on radio signals and to measure bird movement en route (Cochran 1972, 1975, 1987; Cochran et al. 2008; Sapir et al. 2010, 2011b). To estimate the wind encountered aloft, we applied a detailed numerical atmospheric model (Pielke et al. 1992; Sapir et al. 2011b). We hypothesized that lateral drift due to crosswind is conditioned by flight mode and predicted that birds incur a higher degree of drift during flapping compared with soaring gliding during which bee-eaters may fully compensate for the effects of crosswind.

\section{Materials and methods}

Species and study area

The European Bee-eater (Merops apiaster) is a long-distance migrant that feeds on flying insects. It is known to use both flapping and soaring gliding flight during migration (Fry 1984; Sapir et al. 2010, 2011a, b). We trapped migrating bee-eaters (mean body mass $56.3 \mathrm{~g}$ ) during the springs of 2005 and 2006 at Eilat $\left(29^{\circ} 34^{\prime} \mathrm{N}\right.$ $\left.34^{\circ} 58^{\prime} \mathrm{E}\right)$ and Grofit $\left(29^{\circ} 56^{\prime} \mathrm{N} 34^{\circ} 04^{\prime} \mathrm{E}\right)$, located $40 \mathrm{~km}$ apart in the southern part of the arid Arava Valley in Israel.

\section{Bird tracking and flight mode determination}

Following trapping and ringing, each bird was fitted with a 1 -g transmitter $(1.8 \%$ of the average body mass of the birds; model SP2000-HR, Sparrow Systems, Fisher, IL) according to the procedure described elsewhere (Cochran and Wikelski 2005; Sapir et al. 2011a). The transmitter continuously emitted radio signals in the $605-\mathrm{MHz}$ band that was frequency modulated by flight muscle potentials (Lord et al. 1962; Cochran et al. 2008; Sapir et al. 2010). Null reception was evident when the position of the transmitter was $0^{\circ}$ and $180^{\circ}$ relative to the receiving antenna (Cochran 1975; Sapir et al. 2010). We identified bird flight mode (flapping, mixed flight, or soaring gliding) based on wing flap and null reception patterns, as specified in Sapir et al. (2011b); direct observations of feather-tipped marked birds during tracking corroborated this distinction.

We followed the birds using two vehicle-mounted radio telemetry systems, as described in Sapir et al. (2010, 2011a). Triangulation was employed to determine bird location using the Global Positioning System (GPS) time stamp that was synchronized between the GPS devices found in the two vehicles, allowing a maximal time interval during which location was triangulated of $1 \mathrm{~min}$. We measured the error of the directional bearing of the tracking systems using blind measurements to transmitters that were located $0.511 \mathrm{~km}$ away from the tracking vehicles and 
found that the positional error [mean \pm standard deviation (SD)] was $6.1 \pm 4.7^{\circ}$ ( $N=39$ measurements). Due to the technical limitations of bird tracking en route, we were only able to divide the migration routes of all the birds into segments (mean $\pm \mathrm{SD}$ ) $2.4 \pm 3.4 \mathrm{~km}$ long; these segments are the most detailed approximation of the birds' actual flight path as recorded by the tracking systems. In each of the 323 segments that were analyzed, bird flight mode was identified, and the birds' speed and direction were calculated after triangulated bird locations were processed using ArcView 9.3 (ESRI, Redlands, CA). Bird height above the ground was estimated using bearing information received by the antennas and triangulation by a series of measurements made within $1 \mathrm{~min}$, such that some of the measurements were also made in the vertical plane. This was possible because one directional antenna was adjustable on both the horizontal and the vertical planes. This technique is described in detail in Cochran and Kjos (1985). However, due to technical constraints, we were able to determine bird altitude for only about $10 \%$ of the flight segments. Bird altitude was $234 \pm 198 \mathrm{~m}$ above ground (range $10700 \mathrm{~m} ; N=31$ ); this is presumably a substantial underestimation due to difficulties in assessing the altitude of tracked birds that flew at relatively high altitudes in the proximity of the tracking vehicles. Bird altitude above ground was not significantly different between different flight modes (Sapir et al. 2011b).

Application of the regional atmospheric modeling system

We used The Regional Atmospheric Modeling System (RAMS) (Pielke et al. 1992; Walko et al. 2000; Cotton et al. 2003) to model the wind encountered by migrating bee-eaters during cross-country flight (Sapir et al. 2011b) using the simulated $u$ (west east), and $v$ (south north) components of wind velocity. The model was applied with a horizontal grid mesh of $1 \mathrm{~km} \times 1 \mathrm{~km}$, and its vertical mesh size varied by altitude, starting with a 50-m resolution from the surface and increasing by a factor of 1.1 with altitude (e.g., the second vertical grid was $55 \mathrm{~m}$ high from 50 to $105 \mathrm{~m}$ above ground). Since we could not determine bird altitude in most segments, we used wind data from a fixed altitude of $500 \mathrm{~m}$ (Sapir et al. 2011b). We examined the relationship between RAMS-simulated data, estimated with a temporal resolution of $5 \mathrm{~min}$, and ground wind velocity and direction measurements, measured every $10 \mathrm{~min}$. The data were recorded in Hatzeva station $\left(30^{\circ} 47^{\prime} \mathrm{N}, 35^{\circ} 15^{\prime} \mathrm{E}\right)$ during eight consecutive days in May 2005 and obtained from the Israeli Meteorological Service. Simulated wind velocity was positively related to measured wind velocity [regression analysis; simulated wind velocity $(\mathrm{m} / \mathrm{s})=0.58 \times$ observed wind velocity $(\mathrm{m} / \mathrm{s})+0.96(\mathrm{~m} / \mathrm{s}) ;$
$\left.R^{2}=0.52, p<0.001\right]$. The average ( \pm circular SD) difference between measured and RAMS-simulated wind direction was $25^{\circ}\left( \pm 68^{\circ}\right)$ counter-clockwise (see additional details in Sapir et al. 2011b).

\section{Statistical analysis}

Lateral drift can be identified when the perpendicular speed of movement (e.g., Klaassen et al. 2011) relative to the intended migration direction is correlated with crosswind speed. When no such correlation exists (i.e., crosswind does not affect sideways movement), moving animals compensate for lateral displacement by changing their heading towards the direction from where the wind is blowing (Fig. 1). We tested if the degree of lateral drift due to crosswind varied when birds flew using different flight modes by examining the speed of movement perpendicular to the presumed intended migration direction of the birds.

The birds' presumed goal was estimated from the average angle between the starting points of cross-country flights and the locations where bird signals were lost (Green and Alerstam 2002; Sapir et al. 2011a). We found that the average angle, which is the presumable intended destination of the birds, was $359^{\circ}$ ( $N=11$ individuals), and we used $0^{\circ}$ instead to simplify our calculations. Crosswind speed was estimated from RAMS simulations by using the $u$ wind component (in $\mathrm{m} / \mathrm{s}$ ), which is perpendicular to the presumed destination of the birds. Positive values of crosswind speed corresponded to wind blowing from the left to the right of the bird, and vice versa. We also calculated the absolute crosswind speed (in $\mathrm{m} / \mathrm{s}$ ) by multiplying negative crosswind values by -1 and, following Klaassen et al. (2011), we calculated the effect of tailwind on bird forward (toward presumed destination) speed using the $v$ wind component. This calculation was made in order to compare the magnitude of the effect of crosswind on lateral movement to that of tailwind on forward movement (Klaassen et al. 2011). All data on wind and bird flight speed are given in meters per second, unless indicated otherwise.

We tested if segment length differed between the three flight modes using one-way analysis of variance (ANOVA) followed by Bonferroni post hoc comparisons and applied the same test to examine if crosswind speed (with negative and positive values, depending on the direction of the wind; see above) and absolute crosswind speed differed between the three flight modes. Using SPSS ver. 20.0 (SPSS Inc., Chicago, IL), we applied a fully factorial (main effects and interaction terms) analysis of covariance (ANCOVA) with the independent factors crosswind speed (covariate) and bird flight mode (fixed categorical factor), and the dependent factor bird sideways speed (relative to the presumed desired direction; in $\mathrm{m} / \mathrm{s}$ ). The ANCOVA 
model was followed by a linear regression to estimate the slope of the relationship between crosswind speed and bird sideways speed. We similarly applied an ANCOVA with the independent factors tailwind speed (covariate) and bird flight-mode (fixed categorical factor) and the dependent factor bird forward speed. All tests were two sided with critical $\alpha=0.05$. Data are reported as mean \pm SD unless otherwise noted.

\section{Results}

Using the portable radio telemetry systems we followed 11 European Bee-eaters for a total of $810 \mathrm{~km}$ during crosscountry flight over southern Israel (Fig. 2). We analyzed 91 segments from seven birds that employed flapping flight, 141 segments from seven birds that used mixed flight mode, and 91 segments from five birds that soared glided. Alternations between different flight modes were common en route and occurred in all individuals, except for one bird that flapped and another that soared glided throughout

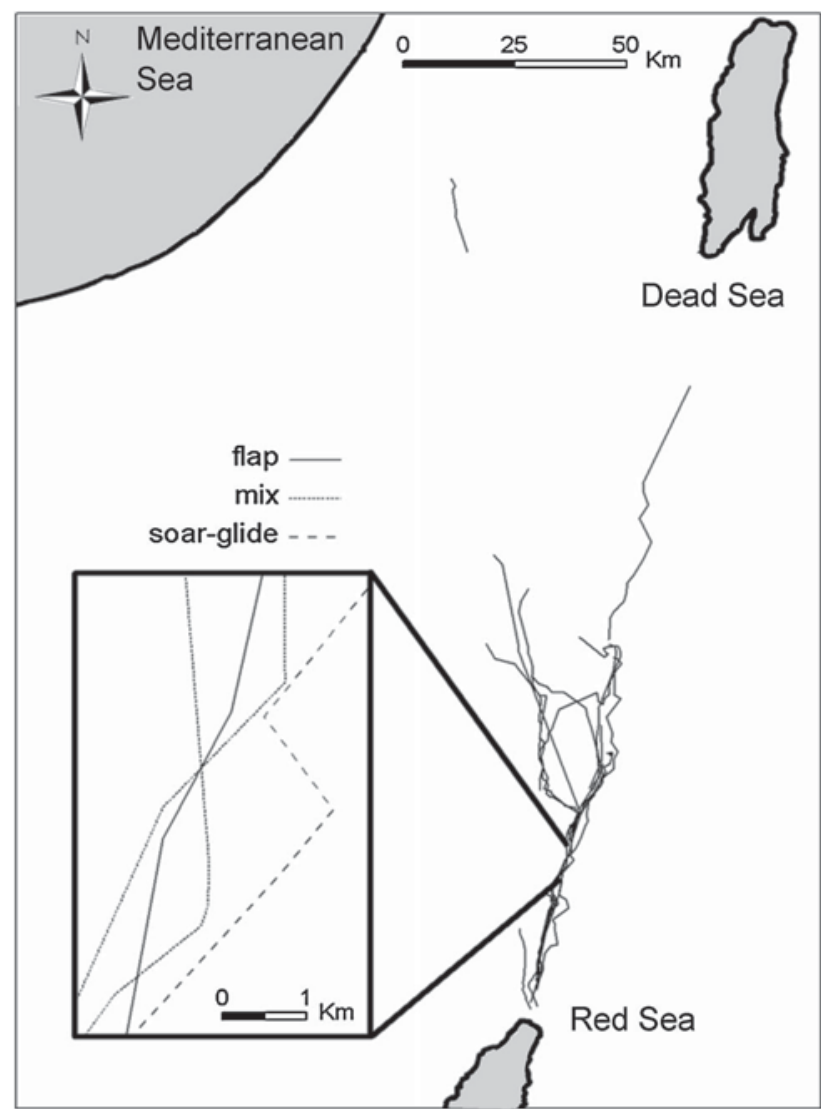

Fig. 2 Flight segments of migrating European Bee eaters (Merops apiaster) that were tracked over southern Israel by portable radio telemetry systems. Shaded shapes Seas. Inset Small area in the Arava Valley over which birds migrated using the three different flight modes their entire tracked journeys. No significant difference was found between the lengths of the segments over which the birds were followed in the different flight modes (one-way ANOVA $\left.F_{2,320}=1.742, p=0.177\right)$. Flight direction in most segments was towards the north, regardless of bird flight mode, as expected during spring migration (Fig. 3a c). Average ( \pm angular SD) flight direction in relation to the true north in segments of flapping, mixed and soaring gliding flight was $9.70 \pm 26.99^{\circ}, 6.98 \pm 45.06^{\circ}$, and 0.06 $\pm 34.38^{\circ}$, respectively.

Crosswind speed significantly varied when birds flew using different flight modes (one-way ANOVA $F_{2,320}=$ 25.116, $p<0.001$ ), with crosswind speed during mixed flight $(1.38 \pm 2.25 \mathrm{~m} / \mathrm{s})$ being significantly higher (Bonferroni post hoc test $p<0.001$ ) than that during soaring gliding $(-0.24 \pm 1.99 \mathrm{~m} / \mathrm{s})$ and flapping flight $(-0.33 \pm 1.44 \mathrm{~m} / \mathrm{s}$; Bonferroni post hoc test $p<0.001$; Fig. 3d f). Crosswind speed during flapping flight was not statistically different from that during soaring gliding flight (Bonferroni post hoc test $p=0.91$ ). Absolute crosswind speed differed between the different flight modes (one-way ANOVA $\left.F_{2,320}=13.238, p<0.001\right)$, with absolute crosswind speed during mixed flight $(2.11 \pm 1.57 \mathrm{~m} / \mathrm{s})$ being significantly higher (Bonferroni post hoc test $p=0.018$ ) than that during soaring gliding $(1.64 \pm 1.12 \mathrm{~m} / \mathrm{s})$ and flapping flight $(1.24 \pm 0.78 \mathrm{~m} / \mathrm{s}$; Bonferroni post hoc test $p<0.001)$. Absolute crosswind speed during flapping flight was not statistically different (Bonferroni post hoc test $p=0.114$ ) from that during soaring gliding flight. Thus, both crosswind speed and absolute crosswind speeds were similar for flapping and soaring gliding segments, while mixed flight segments were generally characterized by higher crosswind speed and absolute crosswind speed.

Crosswind speed significantly affected bird sideways speed (Table 1), yet the effect of flight mode was not statistically significant. The flight mode $\times$ crosswind speed interaction was similarly not significant. These results suggest that bee-eaters drifted laterally due to crosswind regardless of their flight mode, thereby refuting our hypothesis. The results of the regression (Table 1) nevertheless suggest that the birds compensated for most of the lateral drift, as the slope of the regression was 0.31 (during a full drift the slope is expected to equal 1 while during full compensation is slope is expected to equal 0). Moreover, the extremely low $R^{2}$ of the regression (0.01) suggests that lateral drift is not an important factor for explaining the sideways movements of migrating bee-eaters. Consequently, we conclude that migrating bee-eaters fully compensate for crosswinds.

The ANCOVA results for bird forward speed (Table 2) suggest that tailwind speed and the interaction between tailwind speed and flight mode were significant explanatory factors. Thus, the effects of tailwind on bird forward 

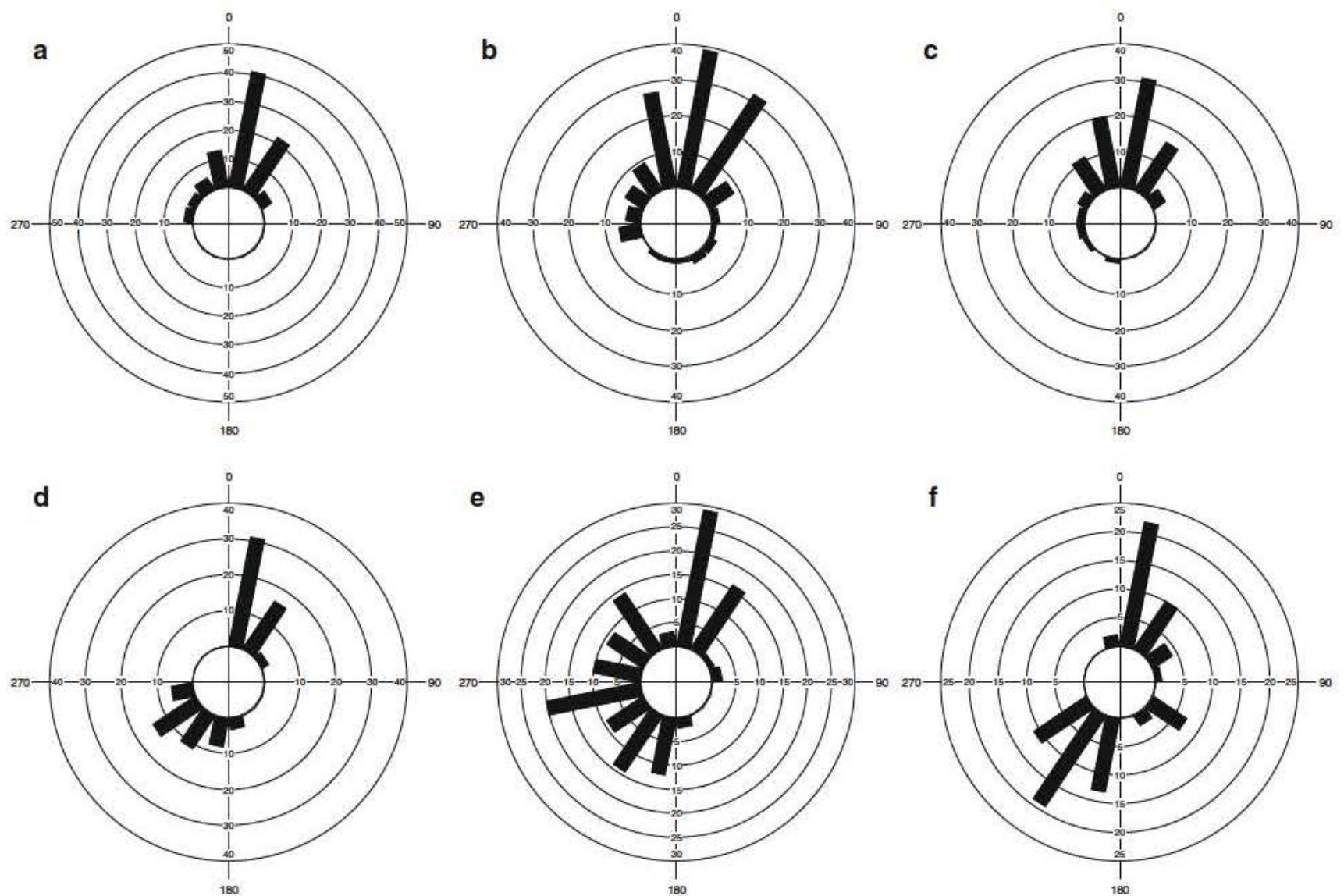

Fig. 3 Bird track direction (a c), and wind direction (d f) of migrating European Bee eaters during flapping (a, d), mixed (b, e) and soaring gliding $(\mathbf{c}, \mathbf{f})$ flight. In the circular diagram panels, notations of different circles depict the frequency of cases

Table 1 Analysis of covariance and regression results for bird sideways speed ${ }^{a}$ (dependent variable) in relation to crosswind speed (covariate) and bird flight mode (independent fixed factor)

\begin{tabular}{|c|c|c|c|c|c|}
\hline ANCOVA source & Sum of squares & $d f$ & Mean square & $F$ & $p$ \\
\hline Corrected model & 304.189 & 5 & 60.838 & 2.046 & 0.072 \\
\hline Intercept & 325.459 & 1 & 325.459 & 10.944 & 0.001 \\
\hline Flight mode & 144.994 & 2 & 72.497 & 2.438 & 0.089 \\
\hline Crosswind & 179.896 & 1 & 179.896 & 6.049 & 0.014 \\
\hline Flight mode $\times$ crosswind & 34.843 & 2 & 17.421 & 0.586 & 0.557 \\
\hline Error & $9,426.965$ & 317 & 29.738 & & \\
\hline Regression model & Intercept $(95 \% \mathrm{CI})$ & \multicolumn{3}{|c|}{ Slope (bird sideways speed) (95\% Cl) } & $R^{2}$ \\
\hline & $0.980\left(\begin{array}{lll}0.365 & 1.596\end{array}\right)$ & \multicolumn{3}{|c|}{$0.307\left(\begin{array}{lll}0.024 & 0.590\end{array}\right)$} & 0.014 \\
\hline
\end{tabular}

ANCOVA, Analysis of covariance; CI confidence interval

${ }^{a}$ Bird speed and wind speed are in meters per second

speed was flight mode-dependent. However, the results of the regressions that were done separately for each flight mode suggest that this effect was only evident for flapping flight, with a positive effect of tailwind speed on bird forward speed. No such effect was found for mixed flight and soaring gliding flight, possibly because no strong headwinds or tailwinds blew while the birds chose to fly in these flight mode, as opposed to flapping flight segments during which most of the birds experienced headwinds. Indeed, different wind conditions prevailed when birds flew using different flight modes (one-way ANOVA $F_{2,320}=11.844, p<0.001$ ), with tailwind speed during 
Table 2 ANCOVA and regression (for each flight mode) results for bird forward speed $^{\mathrm{a}}$ (dependent variable) in relation to tailwind speed (covariate) and bird flight mode (independent fixed factor) ${ }^{a}$ Bird speed and wind speed are
in meters per second

\begin{tabular}{lcrrrr}
\hline ANCOVA source & Sum of squares & \multicolumn{1}{c}{$d f$} & Mean square & \multicolumn{1}{c}{$F$} & \multicolumn{1}{c}{$p$} \\
\hline Corrected model & $1,083.295$ & 5 & 216.659 & 4.665 & $<0.001$ \\
Intercept & $24,526.050$ & 1 & $24,526.050$ & 528.139 & $<0.001$ \\
Flight mode & 279.460 & 2 & 139.730 & 3.009 & 0.051 \\
Crosswind & 491.002 & 1 & 491.002 & 10.573 & 0.001 \\
Flight mode $\times$ crosswind & 331.209 & 2 & 165.605 & 3.566 & 0.029 \\
Error & $14,721.040$ & 317 & 46.439 & & \\
\hline
\end{tabular}

\begin{tabular}{|c|c|c|c|}
\hline Regression model & Intercept $(95 \% \mathrm{CI})$ & Slope (bird sideways speed) $(95 \% \mathrm{CI})$ & $R^{2}$ \\
\hline Flapping flight & $11.102(9.43212 .771)$ & $0.767(0.4191 .116)$ & 0.177 \\
\hline Mixed flight & 8.645 (7.309 9.981) & $0.132\left(\begin{array}{lll}0.319 & 0.583\end{array}\right)$ & 0.002 \\
\hline soaring gliding flight & $9.088\left(\begin{array}{lll}7.965 & 10.331\end{array}\right)$ & $0.207\left(\begin{array}{ll}0.138 & 0.552)\end{array}\right.$ & 0.016 \\
\hline
\end{tabular}

soaring gliding $(0.21 \mathrm{~m} / \mathrm{s})$ being significantly higher (Bonferroni post hoc test $p<0.001$ ) than that during flapping flight $(-2.24 \mathrm{~m} / \mathrm{s})$ and that during mixed flight $(-1.15 \mathrm{~m} / \mathrm{s}$; Bonferroni post hoc test $p=0.003)$. However, we did not find a significant difference in tailwind speed between flapping and mixed flight segments (Bonferroni post hoc test $p=0.138$ ).

\section{Discussion}

Lateral drift due to crosswind did not vary between different flight modes in migrating European bee-eaters, and thus our hypothesis was not supported by the results of the analysis. The birds compensated for most if not all of the crosswind encountered during flight, regardless of their flight mode. Previous studies that investigated different sources for observed variation in lateral drift suggested that when birds lack ground reference marks (e.g., when flying over sea), they substantially drift sideways, whereas when landmarks are visible (e.g., over land), migrants usually fully compensate for crosswind drift (Alerstam 1975; Srygley et al. 1996; Srygley 2001, 2003; Srygley and Dudley 2008; Klaassen et al. 2011). Yet it seems that even when landmarks are available, the variation in animal response to crosswind is still very large (Srygley et al. 1996; Klaassen et al. 2011).

Data from atmospheric simulations suggest that soaring gliding flight is conditioned to intense convective thermals, while flapping flight is usually undertaken when no convection exists. Mixed flight takes place during highly variable convective thermal conditions (Sapir et al. 2011b), and, as our results suggest, commonly occurs when crosswind speed is relatively high. Due to the high prevalence of mixed flight in the migration of European Beeeaters (44\% of all flight segments in the present study) and in several other migrating birds (e.g., common cranes migrating over southern Sweden; Pennycuick et al. 1979), it is important to characterize the specific conditions during which this flight mode takes place and to further explore other consequences (e.g., metabolic and performance related) of this frequently occurring flight mode. The definition and characterization of mixed flight represent a methodological challenge because this flight mode encompasses a wide range of flight behaviors. While both flapping and soaring gliding flight are easily identified by the continuous movement of the wings or the lack thereof, respectively, mixed flight falls in between these two extremes, representing a highly variable flight behavior. As such, it may occur under highly variable environmental conditions that may represent different combinations of winds (the findings of the present study) and convective thermals (Sapir et al. 2011b).

Previous studies that investigated the extent of lateral drift due to crosswind used either local weather measurements (e.g., Riley et al. 1999) or products of low-resolution models that are spatially extensive, usually at a scale of a continent or the entire globe (e.g., Klaassen et al. 2011). The use of detailed numerical simulations, for example, by means of the RAMS, enables the study of bird migration during cross-country flight without the need to sacrifice the resolution of influential environmental parameters for the scale of investigation, and vice versa (Nathan et al. 2005). Additionally, acquiring data on both animal behavior and location using radio-telemetry (Cochran 1975; Cochran and Wikelski 2005; Sapir et al. 2011b) or accelerometery (Holland et al. 2009; Halsey et al. 2011; Nathan et al. 2012) helps decipher how flying animals, such as migrating beeeaters, respond to environmental conditions aloft. The simultaneous acquisition of multiple, high-resolution data is thus necessary for acquiring a better understanding of the causes, mechanisms, and consequences of bird migration and other organismal movement phenomena (Nathan et al. 2008). 
Acknowledgments We would like to thank Reuven Yosef, Tzadok Tzemah, William W. Cochran, Itzik Simhayof, Ofir Altstein, David Troupin, Yitzhak Mahrer, Adi Ben Nun, Erica Kim, and members of the tracking teams and Movement Ecology Laboratory for their assistance. We thank the Israeli Meteorological Service and especially Amos Porat for providing the meteorological measurements and related information. We thank Thomas Alerstam for his constructive comments on a previous version of the manuscript. This work was supported by the US Israel Binational Science Foundation (grant no. 229/2002 \& 124/2004), the Ring Foundation for Environmental Research, and the Robert Szold Fund for Applied Science. N.S. was supported by two Rieger JNF fellowships and a Fulbright doctoral dissertation travel fellowship.

Conflict of interest None.

Ethical standard Bird trapping permits were obtained from the Israeli Nature and Parks Authority (permits 2005/22055, 2006/25555), and the experimental procedure was approved by the Animal Care and Use Committee of the Hebrew University of Jeru salem (permit NS 0607 2).

\section{References}

Alerstam T (1975) Crane Grus grus migration over sea and land. Ibis $117: 489495$

Alerstam T (1979) Wind as selective agent in bird migration. Ornis Scand 10:7693

Alerstam T (1990) Bird migration. Cambridge University Press, Cambridge

Alerstam T, Hedenström A (1998) The development of bird migration theory. J Avian Biol 29:343 369

Alerstam T, Lindström A (1990) Optimal bird migration: the relative importance of time, energy, and safety. In: Gwinner E (ed) Bird migration: the physiology and ecophysiology. Springer, Berlin, pp 331351

Alerstam T, Chapman JW, Bäckman J, Smith AD, Karlsson H, Nilsson C, Reynolds DR, Klaassen RHG, Hill JK (2011) Convergent patterns of long distance nocturnal migration in noctuid moths and passerine birds. Proc R Soc Lond B 278:1339 1346. doi:10.1098/rspb.2010.2106

Baudinette RV, Schmidt Nielsen K (1974) Energy cost of gliding flight in herring gulls. Nature 248:83 84

Bevan RM, Butler PJ, Woakes AJ, Prince PA (1995) The energy expenditure of free ranging black browed albatrosses. Phil Trans R Soc Lond B 350:119 131

Bohrer G, Brandes D, Mandel JT, Bildstein KL, Miller TA, Lanzone M, Katzner T, Maisonneuve C, Tremblay JA (2012) Estimating updraft velocity components over large spatial scales: contrast ing migration strategies of golden eagles and turkey vultures. Ecol Lett 15:96 103

Bruderer B, Liechti F (1995) Variation in density and height distribution of nocturnal migration in the south of Israel. Isr $\mathbf{J}$ Zool 4:477 487

Chapman JW, Reynolds DR, Mouritsen H, Hill JK, Riley JR, Sivell D, Smith AD, Woiwod IP (2008) Wind selection and drift compensation optimize migratory pathways in a high flying moth. Curr Biol 18:514 518

Chapman JW, Nesbit RL, Burgin LE, Reynolds DR, Smith AD, Middleton DR, Hill JK (2010) Flight orientation behaviors promote optimal migration trajectories in high flying insects. Science 327:682 685

Cochran WW (1972) Long distance tracking of birds. In: Galler SR Schmidt Koenig K, Jacobs GJ, Belleville RE (eds) Animal orientation and navigation. NASA, Washington, DC, pp 3959
Cochran WW (1975) Following a migrating peregrine from Wiscon sin to Mexico. Hawk Chalk 14:28 37

Cochran WW (1987) Orientation and other migratory behaviors of a Swainson's thrush followed for $1500 \mathrm{~km}$. Anim Behav 35:927 929

Cochran WW, Kjos CG (1985) Wind drift and migration of thrushes: a telemetry study. Ill Nat Hist Surv Bull 33:297 330

Cochran WW, Wikelski M (2005) Individual migratory tactics of New World Catharus thrushes: current knowledge and future tracking options from space. In: Marra P, Greenberg R (eds) Birds of two worlds. Smithsonian Press, Washington DC, pp 274289

Cochran WW, Bowlin MS, Wikelski M (2008) Wingbeat frequency and flap pause ratio during natural migratory flight in thrushes. Integ Comp Biol 48:134 151

Cotton WR, Pielke RA, Walko RL, Liston GE, Tremback CJ, Jiang H, McAnelly RL, Harrington JY, Nicholls ME, Carrio GG, McFadden JP (2003) RAMS 2001: current status and future directions. Meteorol Atmos Phys 82:5 29

Drake VA, Farrow RA (1988) The influence of atmospheric structure and motions on insect migration. Annu Rev Entomol 33:183 210

Duerr AE, Miller TA, Lanzone M, Brandes D, Cooper J, O’Malley K, Maisonneuve C, Tremblay J, Katzner T (2012) Testing an emerging paradigm in migration ecology shows surprising differences in efficiency between flight modes. PLoS One 7:e35548

Fry CH (1984) The Bee eaters. T. and A. D. Poyser, Calton

Gibo DL, Pallett MJ (1979) Soaring flight of monarch butterflies, Danaus plexippus (Lepidoptera, Danaidae), during the late summer migration in southern Ontario. Can J Zool 57:1393 1401

Green M (2001) Is wind drift in migrating barnacle and brent geese, Branta leucopsis and Branta bernica, adaptive or non adaptive? Behav Ecol Sociobiol 50:45 54

Green M, Alerstam T (2002) The problem of estimating wind drift in migrating birds. J Theor Biol 218:485 496

Gudmundsson GA, Alerstam T, Green M, Hedenström A (2002) Radar observations of Arctic bird migration at the Northwest Passage, Canada. Arctic 55:21 43

Halsey LG, Shepard ELC, Wilson RP (2011) Assessing the devel opment and application of the accelerometry technique for estimating energy expenditure. Comp Biochem Physiol A 158:305 314

Hedenström A (1993) Migration by soaring or flapping flight in birds: the relative importance of energy cost and speed. Phil Trans $\mathrm{R}$ Soc Lond B 342:353 361

Hedenström A, Alerstam T (1995) Optimal flight speed of birds. Phil Trans R Soc Lond B 348:471 487

Holland RA, Wikelski M, Kümmeth F, Bosque C (2009) The secret life of oilbirds: new insights into the movement ecology of a unique avian frugivore. PLoS One 4:e8264

Karlsson H, Henningsson P, Bäckman J, Hedenström A, Alerstam T (2010) Compensation for wind drift by migrating swifts. Anim Behav 80:399 404

Klaassen RHG, Hake M, Strandberg R, Alerstam T (2011) Geo graphical and temporal flexibility in the response to crosswinds by migrating raptors. Proc R Soc Lond B 278:1339 1346

Liechti F (2006) Birds: blowin' by the wind? J Ornithol 147:202 211

Liechti F, Bruderer B (1998) The relevance of wind for optimal migration theory. J Avian Biol 29:561 568

Lord RD, Bellrose FC, Cochran WW (1962) Radio telemetry of the respiration of a flying duck. Science 137:39 40

Nathan R, Sapir N, Trakhtenbrot A, Katul GG, Bohrer G, Otte M, Avissar R, Soons MB, Horn HS, Wikelski M, Levin SA (2005) Long distance biological transport processes through the air: can nature's complexity be unfolded in silico? Divers Distrib $11: 131137$ 
Nathan R, Getz WM, Revilla E, Holyoak M, Kadmon R, Saltz D, Smouse PE (2008) A movement ecology paradigm for unifying organismal movement research. Proc Natl Acad Sci USA 105:19052 19059

Nathan R, Spiegel O, Fortmann Roe S, Harel R, Wikelski M, Getz WM (2012) Using tri axial acceleration data to identify behav ioral modes of free ranging animals: general concepts and tools illustrated for griffon vultures. J Exp Biol 215:986 996

Newton I (2007) The migration ecology of birds. Academic Press, London

Pennycuick CJ (1972) Soaring behaviour and performance of some East African birds observed from a motorglider. Ibis 114:178 218

Pennycuick CJ (2008) Modelling the flying bird. Elsevier/Academic Press, Amsterdam

Pennycuick CJ, Alerstam T, Larsson B (1979) Soaring migration of the common crane Grus grus observed by radar and from an aircraft. Ornis Scand 10:241 251

Pennycuick CJ, Griffin L, Colhoun K, Angwin R (2011) A trial of a non statistical computer program for monitoring fuel reserves, response to wind and other details from GPS tracks of migrating geese. J Ornithol 152:87 99

Pielke RA, Cotton WR, Walko RL, Tremback CJ, Lyons WA, Grasso LD, Nicholls ME, Moran MD, Wesley DA, Lee TJ, Copeland JH (1992) A comprehensive meteorological modeling system RAMS. Meteorol Atmos Phys 49:69 91

Richardson WJ (1978) Timing and amount of bird migration in relation to weather: a review. Oikos 30:224 272

Richardson WJ (1990) Timing and amount of bird migration in relation to weather: updated review. In: Gwinner E (ed) Bird migration: the physiology and ecophysiology. Springer, Berlin, pp 78101

Riley JR, Reynolds DR, Smith AD, Edwards AS, Osborne JL, Williams IH, McCartney HA (1999) Compensation for wind drift by bumble bees. Nature 400:126

Sapir N, Wikelski M, McCue MD, Pinshow B, Nathan R (2010) Flight modes in migrating European Bee eaters: heart rate may indicate low metabolic rate during soaring and gliding. PLoS One 5:e13956
Sapir N, Wikelski M, Avissar R, Nathan R (2011a) Timing and flight mode of departure in migrating European Bee eaters in relation to multi scale meteorological processes. Behav Ecol Sociobiol 65:1353 1365

Sapir N, Horvitz N, Wikelski M, Avissar R, Mahrer Y, Nathan R (2011b) Migration by soaring or flapping: numerical atmospheric simulations reveal that turbulence kinetic energy dictates bee eater flight mode. Proc R Soc B 278:3380 3386

Shamoun Baranes J, van Loon E (2006) Energetic influence on gull flight strategy selection. J Exp Biol 209:3489 3498

Shamoun Baranes J, van Loon E, van Gasteren H, van Belle J, Bouten W, Buurma L (2006) A comparative analysis of the influence of weather on the flight altitudes of birds. Bull Am Meteorol Soc $87: 4761$

Srygley RB (2001) Compensation for fluctuations in crosswind drift without stationary landmarks in butterflies migrating over seas. Anim Behav 61:191 203

Srygley RB (2003) Wind drift compensation in migrating dragonflies Pantala (Odonata : libellulidae). J Insect Behav 16:217 232

Srygley RB, Dudley R (2008) Optimal strategies for insects migrating in the flight boundary layer: mechanisms and consequences. Integ Comp Biol 48:119 133

Srygley RB, Oliveira EG, Dudley R (1996) Wind drift compensation, flyways, and conservation of diurnal, migrant Neotropical Lepidoptera. Proc R Soc Lond B 263:1351 1357

Stull RB (1988) An introduction to boundary layer meteorology. Kluwer Academic, Dordrecht

Thomas PJ, Labrosse AK, Pomeroy AC, Otter KA (2011) Effects of weather on avian migration at proposed ridgeline wind energy sites. J Wildl Manage 75:805 815

Thorup K, Alerstam T, Hake M, Kjellén N (2003) Bird orientation: compensation for wind drift in migrating raptors is age dependent. Proc R Soc Lond B 270:S8 S11

Walko RL, Band LE, Baron J, Kittel TGF, Lammers R, Lee TJ, Ojima D, Pielke RA, Taylor C, Tague C, Tremback CJ, Vidale PL (2000) Coupled atmosphere biophysics hydrology models for environmental modeling. J Appl Meteorol 39:931 944

Williams CB (1957) Insect migration. Ann Rev Entomol 2:163 180 